\title{
CONTRIBUIÇÃO PARA PAISAGEM SONORA DE QUALIDADE NO PARQUE LINEAR BRÁS - LAPA
}

\author{
Claudia Lambertini" e Eliseu Genari* \\ ${ }^{*}$ Arquiteta e Urbanista pela Universidade Presbiteriana Mackenzie. \\ E-mail: arquitetura.claudia@uol.com.br \\ ${ }^{* *}$ Arquiteto e Urbanista, mestrando em Arquitetura e Urbanismo pela Faculdade de Arquitetura e \\ Urbanismo de São Paulo. E-mail: eliseugenari@usp.br
}

\begin{abstract}
RESUMO
A proposta de rebaixamento do sistema de transporte sobre trilhos propiciou vislumbrar a implantação de áreas livres, numa região degradada, ruidosa e dividida pelos trilhos dos trens da CPTM, formando o Parque Linear Brás-Lapa. Este trabalho analisou a necessidade e importância dos espaços livres, especificamente no trecho compreendido entre as ruas Silva Pinto e Anhanguera, localizado no bairro de Santa Cecília e Bom Retiro (São Paulo, Brasil), dentro da área onde seria proposto o Parque Linear Brás Lapa, para o estabelecimento da continuidade do tecido urbano, minimizando a dificuldade de mobilidade e contribuindo para uma paisagem sonora de qualidade.
\end{abstract}

Palavras-chave: Áreas livres, conectividade, paisagem sonora, parque linear.

\section{CONTRIBUTION TO SOUND QUALITY LANDSCAPE AT LINEAR PARK BRÁS-LAPA}

\begin{abstract}
The proposal for lowering the rail transportation system led to glimpse the implementation of free areas in a region degraded, noisy and split by the rails of CPTM trains, forming the Linear Park Brás - Lapa. This study analyzed the need and importance of open spaces specifically in the section between the streets Silva Pinto and Anhanguera, located in the districts Santa Cecilia and Bom Retiro (São Paulo, Brazil), which is inside the area where the Linear Park Brás - Lapa would be proposed, establishing the continuity of the urban area aiming to diminish the mobility difficulty and to contribute to a better sound quality landscape.
\end{abstract}

Key words: Free Areas, Connectivity, Sound Landscape, Linear Park. 


\section{INTRODUÇÃO}

\section{Espaços construídos e espaços livres}

O meio urbano, contido nos limites definidos por legislação municipal, é composto por três sistemas: sistema de espaços construídos, sistema de espaços livres de construção e sistema de espaços de integração urbana (BUCCHERI FILHO e NUCCI, 2006 apud CAVALHEIRO et al, 1999).

Mesclando a infraestrutura verde com a cinza (áreas edificadas), é possível obter efeitos paisagísticos com importantes funções, não só estéticas, mas também auxiliadoras no microclima local. Os espaços livres e verdes necessitam ter uma ambiência urbana agradável, que estimule o uso, a circulação e a permanência das pessoas nos mesmos. Pensando na melhora da qualidade de vida da população local e no desenvolvimento da cidade, propomos a criação de um Parque Linear Brás-Lapa, que ligaria essas duas estações da CPTM através de áreas subaproveitadas nas linhas de trens e seus arredores, formando assim um corredor verde na cidade de São Paulo.

Segundo Botteldooren (2011), podemos destacar conceito geralmente aceito a respeito de soundscapes: "O soundscape é formado dentro de um contexto. Este contexto é formado por todos os estímulos sensoriais, dentre os quais, a visão é o mais importante, e pelo conhecimento acumulado pelas pessoas sobre o espaço, seu uso, seus propósitos, seu significado cultural, suas próprias motivações e propósitos por estarem ali etc. A qualidade do soundscape, no entanto, pode ter efeitos a longo prazo sobre a qualidade de vida e saúde da população".

Segundo Caporrusso (2008), baseada em Vieira (2004), as áreas verdes desempenham diversas funções: a função social relacionada ao lazer; estética, porque compõe uma paisagem diversificada e agradável aos olhos; ecológica, contribuindo com fatores como clima, ar, água, solo; função educativa, no que tange às questões ambientais e psicológica, permitindo o alívio das tensões diárias, lazer, recreação, além de destacar o papel da vegetação como um fator termorregulador do microclima, pois contribui de forma considerável no controle da radiação solar, na temperatura, na umidade do ar, na ação dos ventos e das chuvas e, inclusive, na melhoria da qualidade do ar, ao amenizar sua poluição (MASCARÓ e MASCARÓ, 2009).

Essas massas verdes diminuem a amplitude e a sensação térmica e também auxiliam 
na conservação da água; redução da erosão e economia de energia elétrica; na promoção da biodiversidade; na redução do dióxido de carbono atmosférico; melhorando a qualidade do ar e minimizando a aridez da paisagem (MASCARÓ, 2010).

O ser humano (BOTTELDOOREN, 2011) pode suportar grandes doses de stress (até mesmo o stress causado por excesso de ruído), desde que tenha momentos de recuperação. Pelo foco em espaços abertos, o projeto do soundscape pode contribuir, principalmente, para esses momentos de recuperação.

Para Holtz (2012), o projeto de parques pode levar em conta que a criação do soundscape (experiência auditiva) pode ser análoga à construção do landscape (experiência visual), em que a diversidade de vegetação, mobiliário, texturas, luzes etc. já é feita pelos arquitetos paisagistas de maneira mais evidente. A percepção do soundscape, quando comparada à percepção do landcaspe, se dá de maneira mais sutil, invisível, porém com um componente emocional muito forte. Músicas, sons de crianças, cantos de pássaros etc. podem ser gatilhos para sensações de eventos anteriores, enriquecendo a experiência.

\section{Breve histórico sobre a ferrovia em São Paulo}

A ferrovia teve importante papel no processo de industrialização da Grande São Paulo, ligando os assentamentos urbanos do Estado à capital. A atividade de transporte suburbano de passageiros teve, por muitos anos, caráter secundário, sendo a de transporte de carga a fundamental.

O bairro da Luz teve uma típica ocupação de bairros centrais de São Paulo. A Luz era conhecida como campos do Guarépe ou Guaré, uma planície que se estendia ao longo do rio Tamanduateí, até o rio Tietê. Até 1800, o bairro era pouco denso e ocupado principalmente por chácaras, porém já era visto pela elite como a área mais adequada à expansão residencial, já que a região Sul comportava equipamentos poluidores e de desprestígio, e, na parte leste, o Brás se separava da cidade pela várzea do Tamanduateí. Para a população de alta renda, ficou a região da Luz, ao norte, e a Cidade Nova, a oeste.

A vizinhança do bairro da Luz foi claramente beneficiada com o início do funcionamento da ferrovia, pois a ligava de modo rápido ao porto de Santos e ao interior pau- 
lista, produtor de café. Isto determinou a ascensão econômica, financeira e política de São Paulo.

De acordo com Campos (2005), foi após 1880 que as áreas próximas à Luz atingiram o nível máximo de prestígio. Depois do incêndio de 1946 na Estação da Luz e os problemas gerados pelo aumento do tráfego ferroviário, a população mais abastada começou a se transferir para bairros mais tranquilos, como Campos Elísios, Higienópolis, o entorno da Avenida Paulista, e até o bairro da Liberdade. Assim, a Estação da Luz começava a ser desprezada pelos muito ricos, que preferiam áreas situadas na zona sudoeste da cidade.

Em relação aos problemas estruturais, embora estes se apresentem com intensidade variável, a ferrovia cindiu esse espaço, ocasionando padrões bastante distintos de desenvolvimento urbano, de um lado e de outro. Já a situação geográfica - várzeas dos rios Tietê e Tamanduateí -, se apresenta na forma de inundações constantes.

Embora, na porção mais próxima ao centro histórico da cidade, a cicatriz ferroviária tenha sido mais bem absorvida, apresentando bordas ocupadas, as dificuldades de realizar sua transposição constituem ainda um fator de isolamento de extensas áreas, com a consequente degradação.

A migração das indústrias para o interior, ou para áreas periféricas, deixou como legado instalações por vezes abandonadas ou mal conservadas, ao lado da ferrovia, levando o entorno a uma crescente deterioração.

Na porção mais a oeste, as bordas da orla ferroviária têm ocupação mais recente, e é comum observar grandes áreas ainda vazias, embora não contínuas, junto às ferrovias.

Nos interstícios, tanto a norte quanto a sul, vem ocorrendo intenso processo de verticalização, que demonstra a necessidade de se equacionar a questão da inserção urbanística dos sistemas de transporte de alta capacidade.

Atualmente, muitas das ferrovias urbanas, mesmo as linhas que mantêm operação, apresentam graves problemas, com áreas ocupadas por favelas, criando situações de risco para os moradores e de redução de desempenho operacional, devido à redução da velocidade e à maior incidência de acidentes. 


\section{ÁREA DE ESTUDO}

A área escolhida para a proposta está compreendida entre as ruas Silva Pinto e Anhanguera, localizadas no bairro de Santa Cecília e Bom Retiro. Mas antes foi realizada uma caminhada exploratória, com registros fotográficos, a fim de determinar a situação que se encontrava a região.

O levantamento a pé de toda a área lindeira à linha férrea da CPTM, desde a Estação da Luz até a Estação Barra Funda, nos permitiu levantar e registrar a situação daquelas áreas, para planejar novas formas de ocupação das áreas mal utilizadas em volta da linha férrea.

A grande área foi dividida em trechos: 01, 02 e 03, para melhor compreensão na tomada de decisão quanto às propostas. A partir desta setorização, em termos de ocupação, desocupação, abandono, crescimento e de sons, aprofundamo-nos no trecho que nos chamou mais a atenção: o trecho 02.

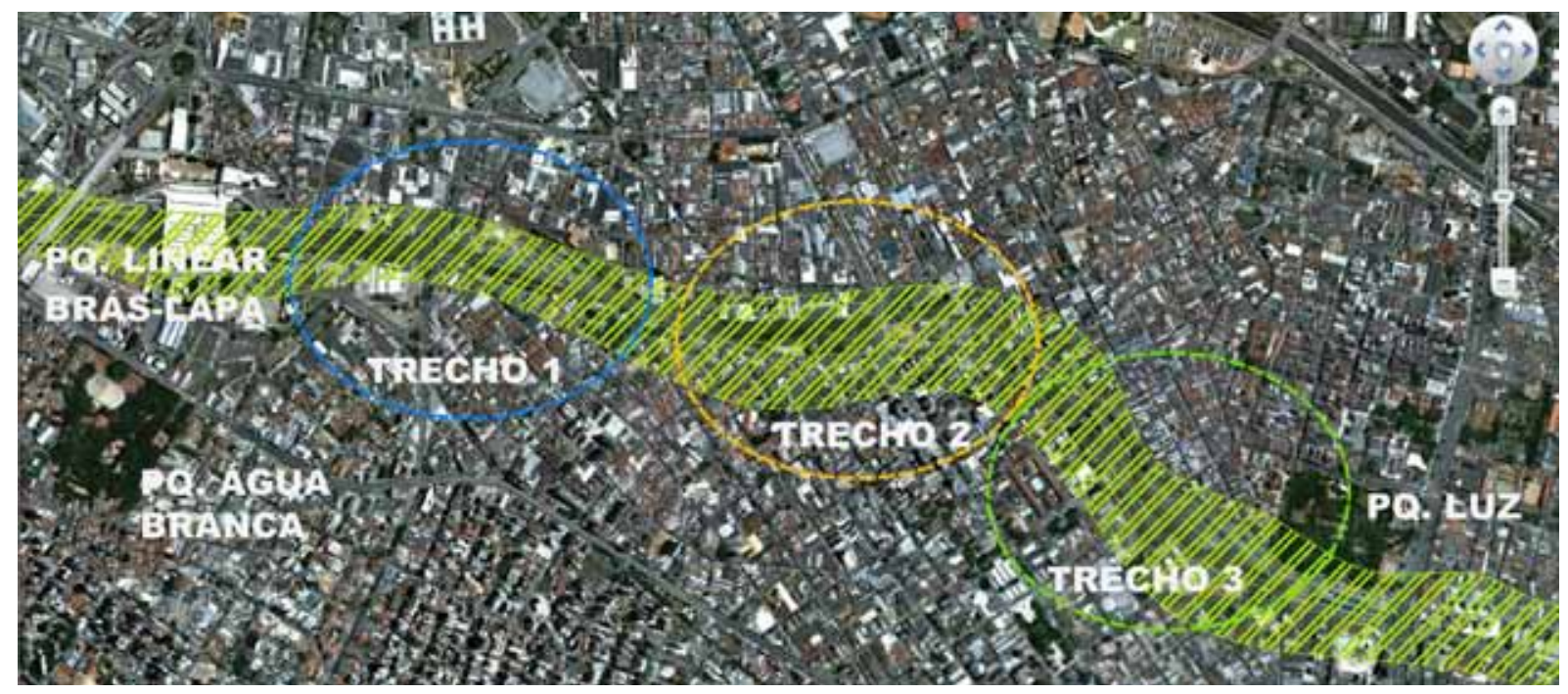

Figura 1: Grande área de estudo - Dividida nos trechos 01, 02 e 03.

Os trechos 01 e 03, mais próximos às estações ferroviárias Barra Funda e Luz, têm um movimento de pessoas, veículos, do comércio etc. tão intenso e movimentado, que quase não se conseguia distinguir os sons dos trens, em relação ao ruído de outras atividades dessas áreas. Os sons dos automóveis na av. Pacaembu, por exemplo, chega a mascarar os sons dos trens. 


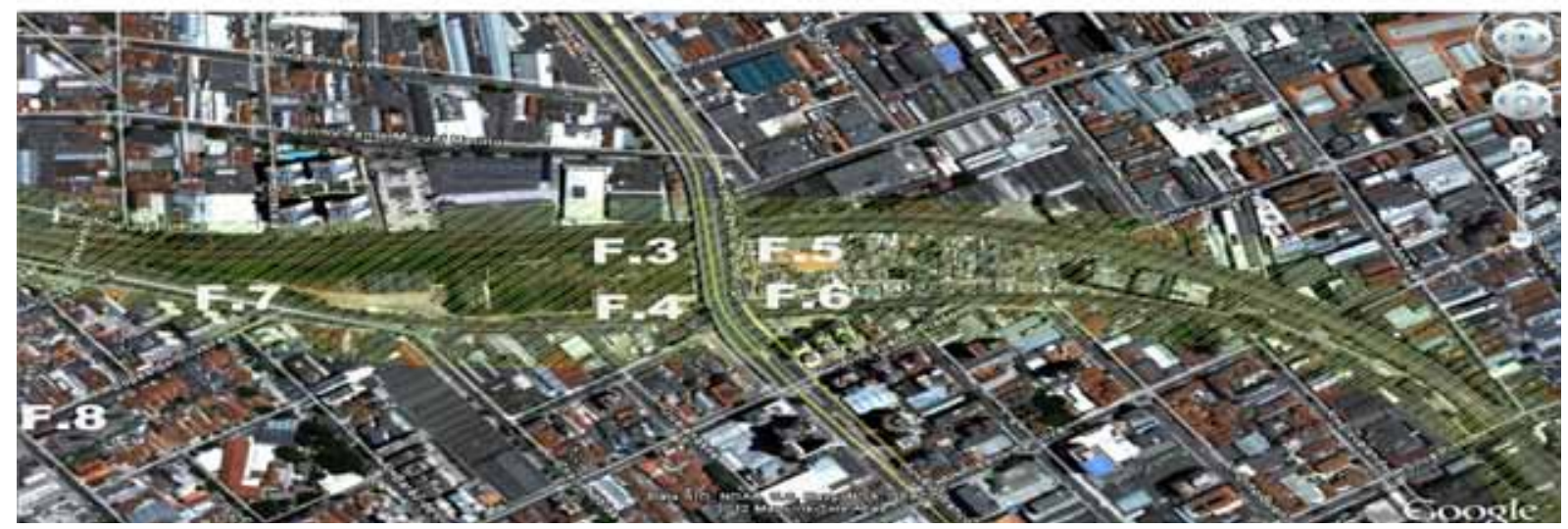

Figura 2: Trecho 02 - Pontos das fotos (F. 4,5,6,7,8 e 9)

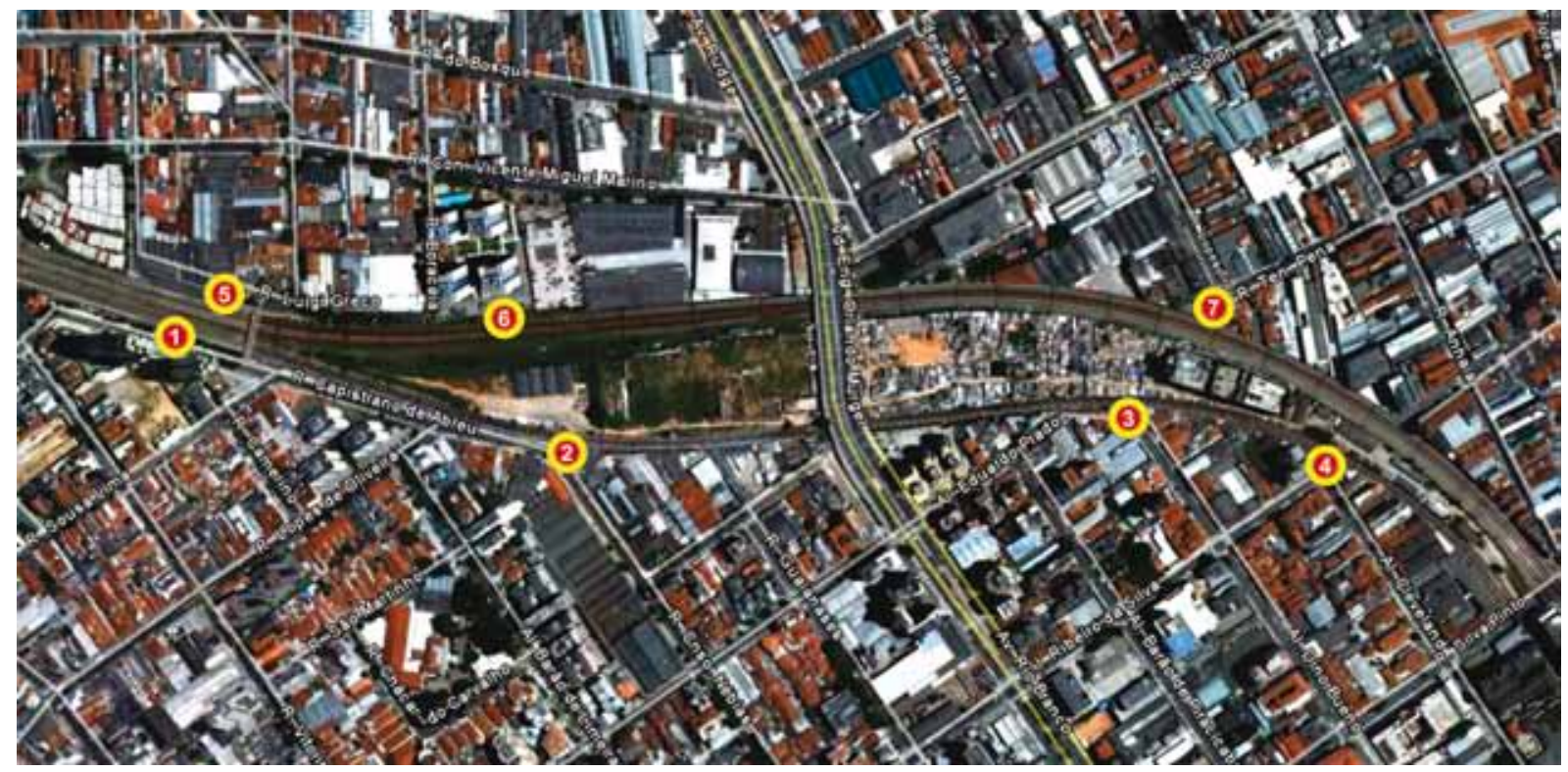

Figura 3: Trecho 02 - Pontos de medição sonora.

No trecho 02, existem terrenos vazios onde aparentemente foram demolidas algumas construções, além da Favela do Moinho, que sofreu com um incêndio parcial, no dia 17 de setembro de 2012. Nesse trecho, apesar de ser uma zona mista, existe a presença de prédios residenciais e de residências. Já neste trecho, o ruído dos trens era percebido com muito mais clareza, pois era uma área realmente mais silenciosa do que os trechos 01 e 03.

No trecho 02, delimitado pelas Ruas Silva Pinto e Anhanguera, percebem-se áreas de permanência e moradia, e muitas pessoas que moram na região, bastante diferente dos trechos 01 e 03 . Outra observação que pôde ser efetuada, foi que, apesar da 
quantidade de pedestres e pessoas que aparentemente residem nessa área, não há áreas de estar. Foram realizadas algumas medições sonoras, a fim de se obter um panorama da influência do ruído gerado pelos trens. Os níveis sonoros medidos em $d B(A)$, sem a passagem dos trens, variava em 52 - $55 \mathrm{~dB}(\mathrm{~A})$; quando da passagem de trem, variou de $70-76 \mathrm{~dB}(\mathrm{~A})$, nos pontos 3, 4, 5 e 6 (Fig. 2).

A partir do Viaduto Engenheiro Orlando Murgel, vemos a ferrovia, que tem dois sentidos de trânsito e se divide em duas linhas, que são espaçadas e ocupadas internamente pela Favela do Moinho. (ver fig. 3, 4, 5 e 6).
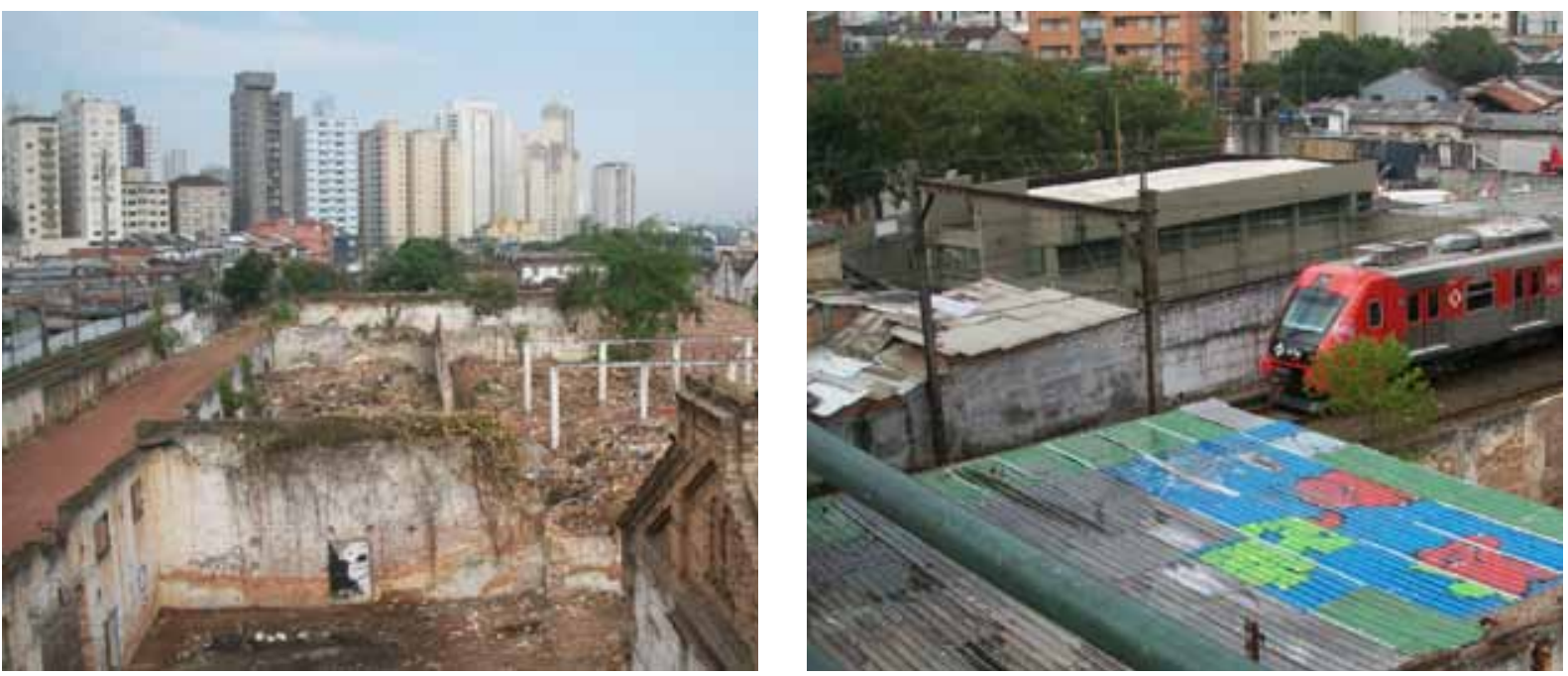

Figura 4 e 5: Trecho 02. Área desocupada na lateral, do viaduto Eng. Orlando Murgel.
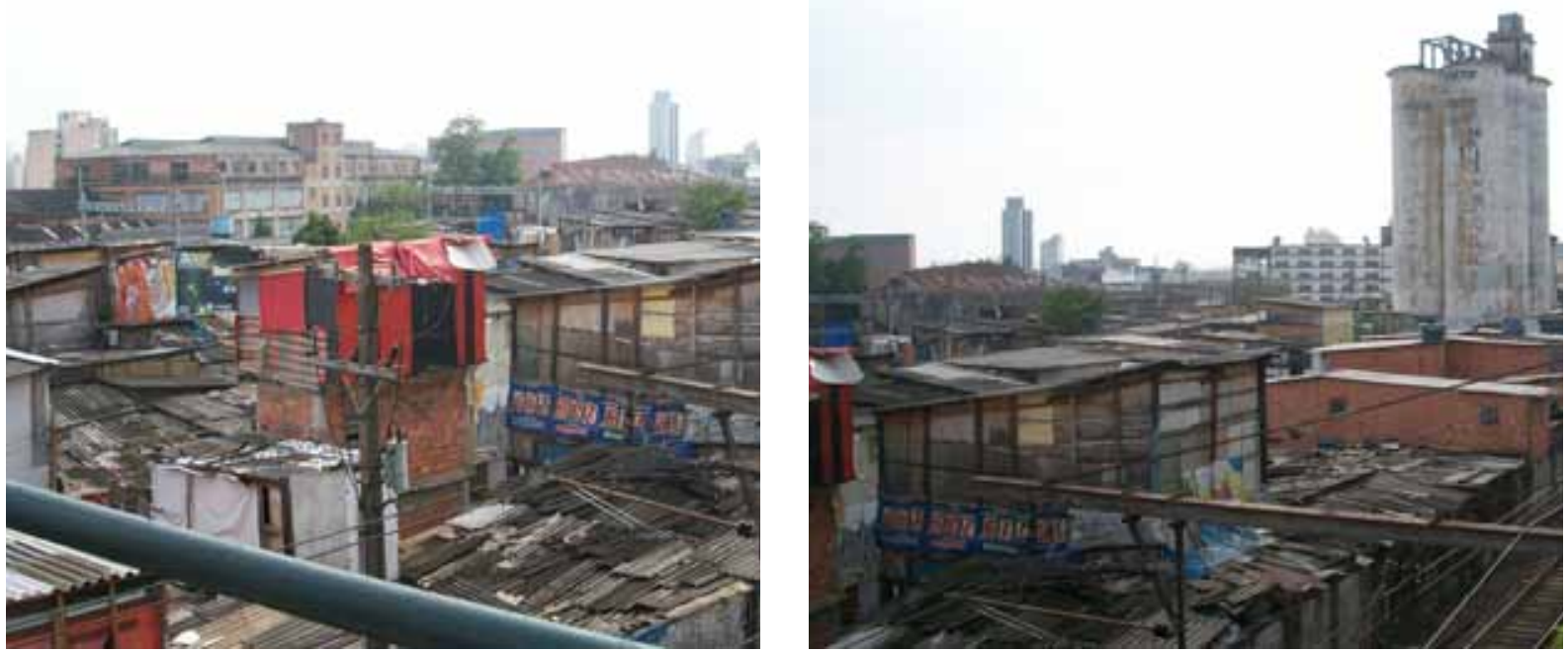

Figura 6 e 7: Trecho 02. Parte Favela do Moinho. Foto tirada do viaduto Eng. Orlando Murgel. 


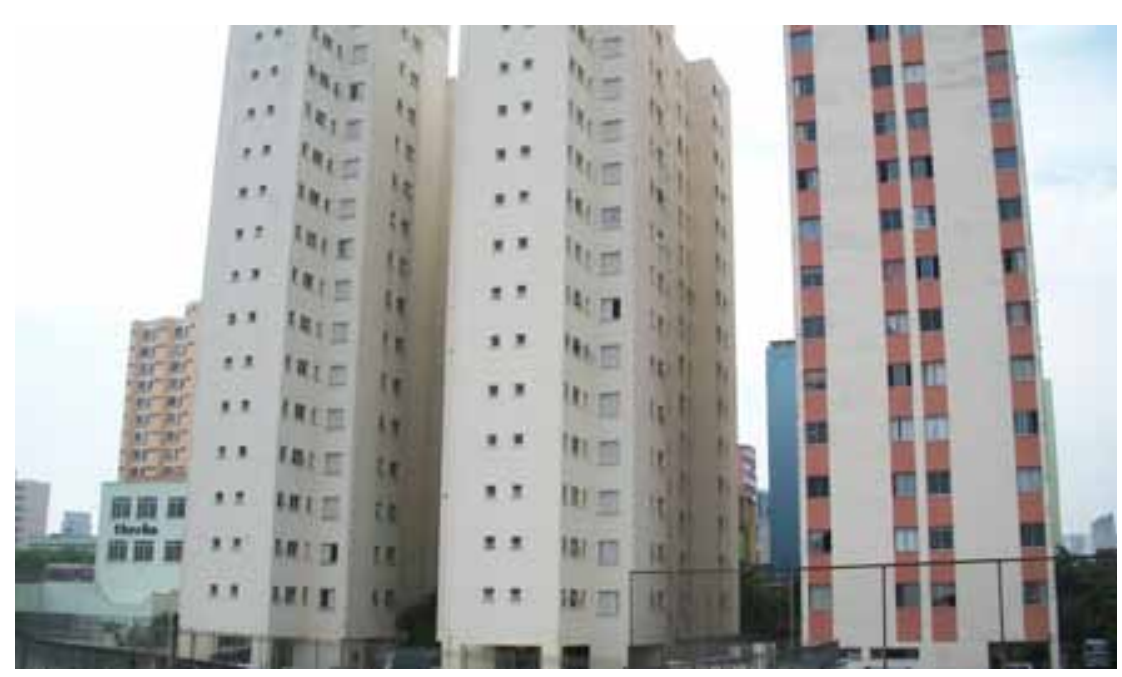

Figura 8: Trecho 02.

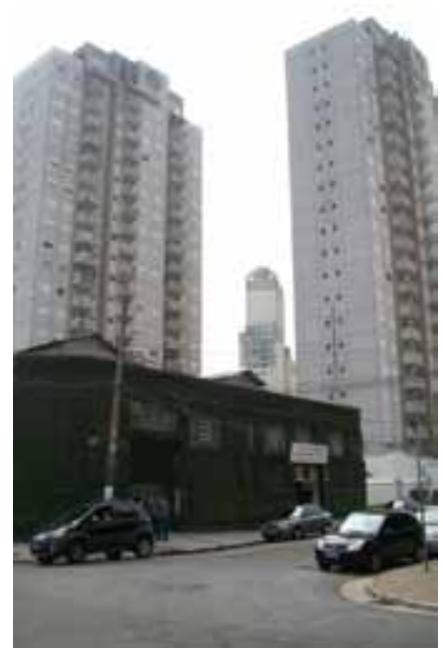

Figura 9: Trecho 02.

Para a criação dessa área livre, propomos a relocação da linha férrea, de modo a que esta ocupe a menor área possível, dentro dos padrões de segurança da CPTM, enterrando-a num determinado trecho, para que sejam criadas ligações entre os dois lados do bairro de Santa Cecília. A superação da barreira da linha férrea se dará por meio de seu enterramento, transformando-a num sistema subterrâneo de aproximadamente um quilômetro de extensão.

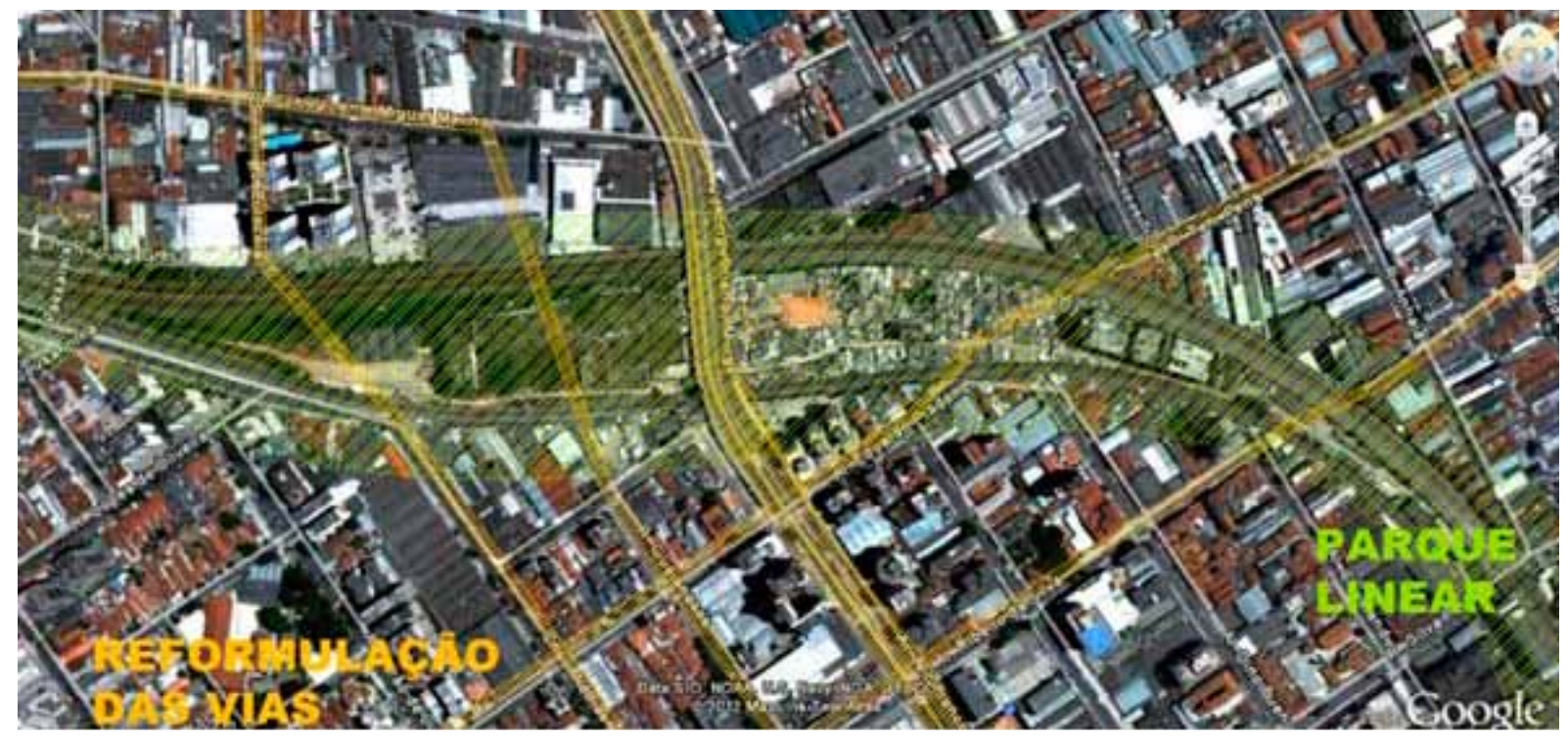

Figura 10: Proposta de uma área livre com ligações entre os dois lados, atualmente divididos pela linha férrea, mas que poderiam ser interligados por um parque linear e dar continuidade às ruas que atualmente são interrompidas pela linha dos trens. 
Como exemplo, na região do Grande ABC - SP, existe a proposta de um metrô subterrâneo, para 2025, a linha 20, que terá 25 quilômetros e ligará São Bernardo ao bairro da Lapa. O remanejamento de linha de trem também é objeto de projeto em Canoas - RS, onde há a proposta de tornar a linha de trem subterrânea em 2,1 quilômetros, na área central da cidade. Este remanejamento, além de melhorar a mobilidade urbana, contará com a expansão do Parque Getúlio Vargas, o que trará maior qualidade de vida para a população.

Neste trabalho, propomos o rebaixamento da linha férrea, como forma de trazer qualidade de vida à população e interligar os bairros que foram cortados pela ferrovia. Esta proposta está inserida num conceito de sustentabilidade, em que o transporte coletivo, de massa, é o principal sistema de mobilidade para longos trajetos. Para os trajetos menores, dentro dos bairros, haveria a possibilidade de andar de bicicleta ou a pé, pelo parque linear que propomos, pois, além de mais agradável, também é mais sustentável do que utilizar o automóvel.

A sustentabilidade tem como pressuposto que as intervenções humanas tenham o menor impacto possível no meio ambiente, e que estas intervenções beneficiem econômica e socialmente os assentamentos humanos, o que traduz o conceito de "pegada leve" ou "pegada ecológica".

A "pegada ecológica", segundo Cecília Herzog (Inverde, 2010), "é uma medida ampla do uso de recursos naturais que enfatiza que o consumo excede os limites ambientais. A pegada ecológica utiliza unidades de medida de área bioprodutiva (hectares globais) para levantar a natureza e a escala dos impactos ambientais de um país, uma região, uma comunidade, uma organização, um produto ou um serviço".

Mobilidade urbana pressupõe intermobilidade entre infraestruturas de transporte coletivo "limpo" (meios de transporte não poluentes), associada ao andar a pé e de bicicleta nas cidades. Uma sociedade sem mobilidade fica estagnada. A "infraestrutura verde" é um conceito que organiza as áreas verdes num sistema interconectado, composto fundamentalmente por núcleos (parques com vegetação e áreas expressivas), fragmentos (praças e pequenas áreas verdes) e corredores verdes (parques lineares). Assim sendo, os parques precisam estar conectados uns aos outros, através de corredores verdes ou caminhos verdes, não sendo suficiente serem núcleos "soltos", na grande malha cinza urbana, já que estes pequenos núcleos não são suficientes para a melhora na qualidade de vida da população local e dos visitantes do bairro. As ciclovias também 
precisam de uma infraestrutura própria, ligando um lugar a outro, e devem ser seguras, afastadas de pistas perigosas, ou delas separadas por meio de barreiras físicas, que garantam a sua segurança e que possam fazer outros caminhos, em que o carro não passe, pois é extremamente interessante que os usuários das ciclovias passem por ambientes onde a poluição sonora seja mínima, e onde a paisagem seja agradável.

Segundo Miranda Martinelli Magnoli, o espaço livre pode ser definido como todo espaço em áreas urbanas não cobertas por edifícios. Porém percebemos que a população não cria vínculos com esses pequenos espaços "soltos" na cidade. Para que isto aconteça, é necessário, não que exista grande quantidade de pequenos jardins separados pelos edifícios da cidade, mas que se possa contar com áreas livres maiores, que sejam percebidas pela sociedade como parques, nas escalas dos bairros, metrópoles, sub-regiões etc.

Outro problema dos parques paulistanos é a proximidade espacial, pois muitos se encontram distantes de glebas residenciais e, por isto, o usuário depende da mobilidade urbana para chegar aos parques.

"Andar a pé constitui a forma mais direta de provimento individual dos meios de transporte." Vasconcellos

"O deslocamento a pé é um dos mais importantes modos de transporte urbano. É o modo mais utilizado para percorrer pequenas distâncias, incluindo a complementação das viagens realizadas por outros modos de transporte." Ferraz e Fontes

"Estes andarilhos renitentes são também viajantes no sistema urbano, e o planejamento deve reconhecer que andar a pé é, e permanecerá uma forma de transporte válida para a maioria das pessoas." Tolley e Torton

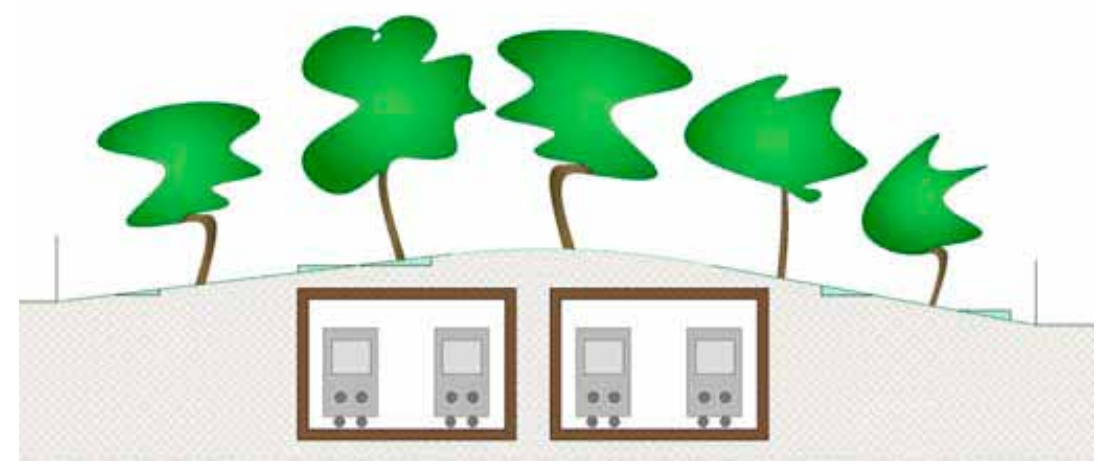

Figura 11: Corte esquemático para a proposta de enterrar linha férrea no trecho 02. 


\section{CONSIDERAÇÕES FINAIS}

De toda a área analisada, o trecho 02 foi o que mais nos chamou a atenção, pelo potencial de se tornar um polo transformador da região. Acreditamos que, com a relocação da linha férrea e seu rebaixamento, poderá ser criado um parque linear, ligando a Fundação Memorial da América Latina e o Parque da Luz, além de servir como local de lazer para a população local, e eliminar a barreira atualmente existente - linha férrea.

Por meio desta proposta, será possível ligar os dois lados da ferrovia, que se desenvolveram de formas diferentes, mas que, ao serem religados, iniciarão um processo de qualificação natural da área, pois esta deixará de ser a borda do bairro, para se tornar uma área de lazer e descanso para os moradores do bairro.

Proposta de formação de redes de áreas verdes e espaços públicos de uso coletivo Encadeamento e hierarquização, de acordo com o porte, abrangência e função.

A cidade de São Paulo atualmente é formada por bairros que muitas vezes não se interligam com os vizinhos. A Prefeitura de São Paulo criou instrumentos legais, como a Operação Urbana Lapa - Brás, que tinha como objetivo a reestruturação de bairros como Santa Cecília e Bom Retiro, que ainda possuem áreas livres que necessitam de qualificação.

Os bairros que sofreram com a desvalorização imobiliária, geralmente, são os que possuem áreas livres que precisam de requalificação urbana, com novas infraestruturas e novos projetos urbanísticos. Por possuir estas características, a área de estudo, nos arredores da Favela do Moinho, na área central da cidade, foi selecionada.

A proposta de relocação da via férrea - e assim ganhar mais espaço e ligar os bairros que foram separados pela ferrovia, tirando partido da implantação do terreno - poderá melhorar a qualidade de vida dos moradores da região, que atualmente sofrem com o ruído causado pelos trens.

Tirando partido da implantação do terreno, propomos enterrar a linha férrea, formando uma barreira acústica natural através do terreno, e ganhando espaço para a criação de um parque, que, além de contribuir para a redução dos ruídos, também poderá colaborar com a melhora da experiência sonora. 
A paisagem sonora tem, como principais aspectos, o visual da paisagem, que colabora para que o usuário não preste atenção ao ruído de fundo, e as barreiras acústicas, que absorvem e diminuem os ruídos da cidade. O Parque Linear, com o enterramento da linha férrea e tratamento sustentável da paisagem, colabora com a paisagem sonora, para o relaxamento dos usuários do parque.

A remoção da população das favelas e cortiços existentes no local é ponto fundamental para a recuperação da área. Para isto, deve ser pensada a construção de Habitação de Interesse Social na região, para que esta população também possa utilizar o parque proposto.

\section{REFERÊNCIAS BIBLIOGRÁFICAS}

AXELSSON, Ö. The ISO 12913 series on soundscape. Forum Acusticum 2011. Aalborg, Dinamarca: [s.n.]. 2011.

AXELSSON, Ö.; NILSSON, M. E. On sound source identification and taxonomy in soundscape research. Internoise 2010. Lisboa, Portugal: [s.n.]. 2010.

AXELSSON, Ö.; NILSSON, M. E.; BERGLUND, B. A principal components model of soundscape perception. The Journal of Acoustical Society of America, Novembro, 2010. 2836-2846.

BERGLUND, B.; NILSSON, M. E.; AXELSSON, Ö. Soundscapes psychophysics in place. Internoise 2007. Istanbul: Available on CD. 2007.

BOTTELDOOREN, D. et al. Understanding urban and natural soundscapes. Forum Acusticum 2011. Aalborg, Dinamarca: [s.n.], 2011.

CAMPOS, Eudes. Nos caminhos da Luz, antigos palacetes da elite paulistana. Anais do Museu Paulista, v. 13, n. 1. São Paulo: USP, 2005.

HOLTZ, Marcos Cesar de Barros. Avaliação qualitativa da paisagem sonora de parques urbanos. Estudo de caso: Parque Villa Lobos, em São Paulo. Dissertação (Mestrado em Tecnologia da Arquitetura) - FAUUSP. São Paulo, 2012. 
MAGNOLI, Miranda Martinelli. O parque no desenho urbano. Revista Paisagem e Ambiente - Ensaios, São Paulo, n. 21, 2006.

MASCARÓ, L.; MASCARÓ, J. J. Ambiência urbana. 1 ed. Porto Alegre: +4, 99 p., 2009.

VEDANA, Viviane. Territórios sonoros e ambiências: etnografia sonora e antropologia urbana. Revista lluminuras, Rio Grande do Sul, n. 25, 2010.

ZANNIN, P. H. T. Incômodo causado pelo ruído urbano à população de Curitiba. Rev. Saúde Pública, São Paulo, n. 4, v. 36, 2002. 